\title{
Antitoxin production in antibiotic-associated colitis?
}

\author{
AH LISHMAN, * IJ AL-JUMAILI, $\dagger$ AND CO RECORD* \\ From the Departments of *Gastroenterology and $\dagger$ Microbiology, Royal Victoria Infirmary, \\ Newcastle upon Tyne NE1 4LP, UK
}

SUMMARY The production of antitoxin after Clostridium difficile-induced diarrhoea has not been reported previously. The stool of a patient with prolonged antibiotic-associated diarrhoea contained $C$. difficile toxin, and the serum neutralised the cytopathic effect of $C$. difficile toxin in tissue culture.

In recent years Clostridium difficile has been implicated as the causative organism in pseudomembranous colitis and some cases of antibiotic-associated colitis, by the production of an endotoxin, ${ }^{1-4}$ but so far workers have failed to demonstrate antitoxin production in such patients. ${ }^{5}$ We report a patient in whom antitoxin production appears to have occurred.

\section{Case history}

A 73-year-old woman with a fractured neck of femur was given oral flucloxacillin, $500 \mathrm{mg}$ four times a day, after internal fixation. Five days later she developed diarrhoea, and cephradine was substituted for the flucloxacillin. After a further two weeks a stool sample was examined specifically for $C$. difficile, and both the organism and its toxin were identified. However, by this time the cephradine had been discontinued, the diarrhoea had abated, and the patient had been discharged, so no further action was taken. One week later the patient was readmitted with a three-day history of severe diarrhoea with incontinence. Sigmoidoscopy showed mild inflammatory changes but no pseudomembrane. $C$. difficile and its toxin were again isolated, and a diagnosis of antibiotic-associated colitis was made. The patient received oral vancomycin, and the diarrhoea ceased.

A sample of the patient's serum taken during her second admission, one month after the onset of diarrhoea, and a further sample taken four months later were investigated for the presence of neutralising activity against $C$. difficile toxin.

Accepted for publication 28 May 1980

\section{Methods}

Toxin and its neutralisation were assayed by the method described by Rifkin $e t$ al.$^{1}$ using confluent monolayers of HeLa cells cultured in Eagle's MEM solution (Flow Laboratories). Equal quantities of the patient's serum and her own faecal filtrate were incubated at room temperature for $\mathbf{3 0}$ minutes, and $0.2 \mathrm{ml}$ was inoculated into tissue culture. The patient's serum was also incubated with faecal filtrates from four other patients known to contain $C$. difficile toxin. Serial dilutions of the patient's serum were incubated with a filtrate containing a known concentration of toxin. As controls, toxin was incubated with sera from one patient with Crohn's disease, two with ulcerative colitis, one with acute infective diarrhoea, six healthy volunteers, and one of the authors (AL).

\section{Results}

The patient's initial serum neutralised the cytopathic effect caused by her own faecal filtrate and that of all four other patients with antibiotic-associated diarrhoea, the neutralising effect being seen at a dilution of 1 in 1000 . The serum sample taken four months after the diarrhoea had ceased (the patient having remained well in the intervening period) still showed a neutralising effect but only at a dilution of $1 / 10$.

Of the control sera, all but one showed no neutralising effect, the exception being the serum of one of the authors, in whom the titre was $1 / 1000$. A second sample taken 10 weeks later showed a neutralising effect at a dilution of $1 / 100$. Both stool cultures and toxin assay were negative, and there was no history of antibiotic ingestion in the past two years or of diarrhoea within the past six months, but the author had frequently handled infected specimens during the previous year. 


\section{Discussion}

The proliferation in the colon of $C$. difficile with the production of a cytopathic endotoxin after treatment with one of a wide range of antimicrobial agents is now well established as the cause of pseudomembranous colitis and up to $20 \%$ of cases of antibioticassociated diarrhoea. Previous work has failed to show the presence of the organism, toxin, or antitoxin in the serum of patients with $C$. difficile-associated colitis in either the acute or convalescent phase, ${ }^{5}$ and it has therefore been suggested that the toxin is not absorbed in significant quantities, its effect being entirely local. The case reported above suggests that this is not necessarily so, and that antitoxin production may take place.

It is possible that the neutralising effect seen in this patient may be a non-specific effect of the serum or an antitoxin to another organism such as Clostridium sordellii, the antitoxin to which is known to neutralise $C$. difficile toxin and indeed has been used to identify $C$. difficile toxin in most of the work done so far. However, the fact that the serum taken in relation to the proven infection with $C$. difficile showed a titre of $1 / 1000$ while that taken four months later had fallen to $1 / 10$ strongly suggests that antitoxin specific to $C$. difficile has been demonstrated.

It is more difficult to explain the persistently raised titre seen in the serum of one of the authors. This again may be due to a cross-reaction with another organism or possibly to handling infected specimens. It is significant that the only two samples to show a neutralising effect were from people who had been exposed to $C$. difficile, and this underlines the care that should be taken when handling specimens which may contain this potentially dangerous organism.

A broad clinical spectrum is seen in $C$. difficileassociated colitis ranging from minimal diarrhoea to pseudomembranous colitis, and yet we have found that toxin is present in the faeces of such patients in the same range of concentration, irrespective of the severity of the disease. This suggests that there are other factors involved in the pathogenesis of the disorder, and it is possible that the ability of the patient to produce antitoxin and the rate at which he is able to do so may affect the severity of the clinical response to the presence of toxin in the colon and may also give protection against further exposure to $C$. difficile. While $C$. difficile is rarely found in the faeces of normal adults, the incidence of the organism and, to a lesser extent, its toxin is relatively high in apparently healthy infants, ${ }^{6} 7$ and it may be that the ability to produce antitoxin is developed at this stage, giving comparative immunity on re-infection in adulthood. Further studies are in progress to ascertain the role of antitoxin production in C. difficileassociated colitis.

\section{References}

${ }^{1}$ Rifkin GD, Fekety FR, Silva J Jr, Sack RB. Antibioticinduced colitis; implications of a toxin neutralised by C. sordellii antitoxin. Lancet 1977;2:1103-7.

2 Larson HE, Price AB. Pseudomembranous colitis: presence of clostridial toxin. Lancet 1977;2:1312-4.

${ }^{3}$ George WL, Sutter VL, Goldstein EJC, Ludwig SL, Fingold SM. Aetiology of antimicrobial-agent-associated colitis. Lancet 1978;1:802-3.

4 Bartlett JG, Moon N, Chang TW, Taylor N, Onderdonk AB. Role of Clostridium difficile in antibiotic-associated pseudomembranous colitis. Gastroenterology 1978;75: 778-82.

${ }^{5}$ Bartlett JG. Antibiotic-associated colitis. Clin Gastroenterol 1979;8:783-801.

- Hall K, O'Toole E. Intestinal flora in newborn infants with description of a new pathogenic anaerobe Bacillus difficilis. Am J Dis Child 1935;49:390-402.

${ }^{7}$ Larson HE, Price AB, Honour P, Borriello SP. Clostridium difficile and the aetiology of pseudomembranous colitis. Lancet 1978;1:1063-6.

Requests for reprints to: Dr AH Lishman, Department of Gastroenterology, Royal Victoria Infirmary, Newcastle upon Tyne NE1 4LP, UK. 